\title{
LA CONSTITUCIÓN DE 1980 COMO FUNDAMENTO Y ORIGEN DE UNA TEORÍA CONSTITUCIONAL DE LA IRRETROACTIVIDAD
}

\author{
SABINA SACCO AQUINO*
}

\begin{abstract}
RESUMEN: El presente artículo plantea una teoría de la irretroactividad basada en la Constitución de 1980. Hoy en día no es posible limitar el estudio de la irretroactividad al Derecho Civil o a los principios generales de derecho; los avances en nuestra Carta Fundamental hacen necesario enfocar la materia desde una perspectiva constitucional. Este artículo sostiene que actualmente los fundamentos de los principios de irretroactividad de las normas y de intangibilidad de las situaciones jurídicas creadas (más conocido como la teoría de los derechos adquiridos) se encuentran en la Constitución Política, particularmente en el artículo 19 Nos 24 y 26. En este sentido, la Constitución de 1980 otorga a los derechos y situaciones jurídicas una intangibilidad consistente en la prohibición al legislador de que dichos derechos o situaciones jurídicas sean restringidos o limitados más allá de su esencia sin mediar expropiación, ya sea como resultado de la incorporación de dichos derechos o titularidades al patrimonio de su titular, donde quedan protegidos por la garantía del derecho de propiedad contenida en el Art. $19 \mathrm{~N}^{\circ} 24$, ya sea como consecuencia de la protección directa que ofrece el Art. $19 \mathrm{~N}^{\circ} 26$ a los derechos constitucionales. Esta intangibilidad constitucional constituye hoy en día el fundamento real para impedir que una norma posterior afecte derechos o situaciones jurídicas creadas bajo el imperio de una norma anterior.
\end{abstract}

Palabras clave: Irretroactividad, intangibilidad, derechos adquiridos, derecho de propiedad, esencia del derecho.

ABSTRACT: This article proposes a theory of non-retroactivity based on the Constitution of 1980. Today it is not possible to limit the study of the principle of non-retroactivity to Civil Law or to the general principles of law; the developments in the Chilean Constitution require a constitutional approach to the subject. This article submits that the foundations of the principles of non-retroactivity of legal rules and inviolability of vested rights are found in the Constitution of 1980, particularly under Article 19 Nos 24 and 26. In this regard, the Constitution of 1980 provides vested rights and other legal entitlements with an inviolability that prevents these rights or entitlements from being restricted or limited by law beyond their essence unless there is expropriation. This inviolability attaches to vested rights and other entitlements as a result of their being deemed acquired by their titleholder and thus covered by the protection granted to property rights under Article $19 \mathrm{~N}^{\circ} 24$, or as a result of the direct protection afforded to constitutional rights by Article 19 № 26. This constitutional inviolability is today the effective legal basis for preventing subsequent laws from affecting rights or entitlements created under the scope of previous laws.

Key words: Irretroactividad, intangibilidad, derechos adquiridos, derecho de propiedad, esencia del derecho.

\footnotetext{
${ }^{*}$ Miembro del Departamento de Arbitraje Internacional de White \& Case LLP, Washington, D.C.; Abogada, Pontificia Universidad Católica de Chile; LL.M., Harvard Law School. La autora quisiera agradecer a Alejandro Vergara Blanco por sus valiosos consejos e infinita paciencia.
} 


\section{INTRODUCCIÓN}

Siguiendo a los juristas franceses, la doctrina chilena tradicionalmente ha enfocado los principios de irretroactividad de las normas y de intangibilidad de las situaciones jurídicas creadas (o teoría de los derechos adquiridos) desde una perspectiva legalista. En efecto, las normas que hasta ahora han servido de base para las teorías tradicionales sobre irretroactividad e intangibilidad -principalmente el Código Civil y la Ley sobre Efecto Retroactivo de las Leyes- son de rango legal. Sin embargo, es este rango legal el que constituye el talón de Aquiles de estas principios: ya que las leyes que los consagran pueden ser derogadas por normas de superior o incluso igual jerarquía, el principio de irretroactividad y la teoría de los derechos adquiridos quedan reducidos a simples declaraciones de buenas intenciones que obligan al juez pero no al legislador.

Sin embargo, hoy en día no es posible limitar el estudio de la irretroactividad de la ley al Derecho Civil o a los principios generales de derecho. La Constitución de 1980 ha provocado un cambio radical en la normativa que sirve de base a las teorías sobre irretroactividad y seguridad jurídica, lo que hace necesario enfocar estas teorías desde una perspectiva constitucional.

Un primer acercamiento a una teoría constitucional de la irretroactividad y de derechos adquiridos es a través del Art. 19 N² 24 de la Constitución de 1980. La teoría de los derechos adquiridos postula que los derechos que se adquieren bajo la vigencia de una determinada ley se convierten en bienes que entran al patrimonio de sus titulares, quienes ejercerían un derecho de dominio sobre estos derechos (práctica jurídica que ha sido bautizada por Vergara Blanco con el nombre de "propietarización de los derechos" ${ }^{\prime)}$. En consecuencia, leyes posteriores no pueden afectar esos derechos adquiridos ya que estos gozan de la inviolabilidad de la propiedad. En otras palabras, la irretroactividad de las normas y la intangibilidad de los derechos adquiridos surgirían como efecto del manto protector del derecho de propiedad. Ya que la protección que otorga el derecho de propiedad está determinada por el Art. $19 \mathrm{~N}^{\circ} 24$ de la Constitución Política, habría que concluir que el principio de irretroactividad y la teoría de los derechos adquiridos se encuentran hoy en día regidos por las normas constitucionales que regulan el derecho de propiedad, y que las normas del Código Civil y la Ley de Efecto Retroactivo de las Leyes sobre esta materia se encuentran obsoletas.

Pero el estudio constitucional de las reglas sobre irretroactividad no se limita al estudio de la garantía constitucional del derecho de propiedad. La Constitución de 1980 contempla una norma específica sobre seguridad jurídica que podría constituir el fundamento de una teoría moderna sobre irretroactividad e intangibilidad: el artículo $19 \mathrm{~N}^{\circ} 26$. En efecto, el Art. $19 \mathrm{~N}^{\circ} 26$ de la Constitución Política otorga protección a los derechos establecidos por la Constitución, prohibiendo que leyes posteriores afecten la esencia o libre ejercicio de dichos derechos. Por esta vía, la Constitución Política consagra una intangibilidad directa a los derechos que ella establece, intangibilidad inherente que surge por su calidad de derechos y no por su calidad de bienes susceptibles de apropiación.

${ }^{1}$ Vergara Blanco (1991-1992) p. 281. 


\section{ALGUNAS CONSIDERACIONES GENERALES SOBRE IRRETROACTIVIDAD E INTANGIBILIDAD}

Antes de entrar de lleno a la materia que nos ocupa, corresponde hacer algunas precisiones respecto de los conceptos de irretroactividad e intangibilidad. Aunque estos conceptos están íntimamente ligados, tienen existencia independiente. Mientras la irretroactividad dice relación con la mutabilidad de las normas, la intangibilidad incide en la estabilidad de las situaciones jurídicas creadas por dichas normas. Sin embargo, históricamente ambos conceptos han sido confundidos y desarrollados simultáneamente o en forma superpuesta por los tratadistas.

\subsection{AMBIGÜEDAD DEL TÉRMINO "RETROACTIVIDAD”}

El estudio de la retroactividad de las normas es un campo ambiguo y engañoso. Ninguna ley es retroactiva stricto sensu, puesto que la ley no puede ni reglamentar, ni modificar el pasado, sino solo extender sus consecuencias en el presente a situaciones que se produjeron en el pasado. Como señala López Menudo, "en puridad, ni siquiera es atribuible a la ley -aunque a esta le sea dable crear ficciones jurídicas como es la retroactividad- el poder de 'accionar hacia atrás', porque el pasado también es irrecuperable para las leyes; (...) la norma solo puede determinar un comportamiento futuro, no un pretérito; por tanto, 'retroactividad' de una norma solo puede significar que en su aplicación futura serán tratados con arreglo a la norma también aquellos hechos que acontecieron con anterioridad a su entrada en vigor. En suma, se quiere decir que no son las normas las que retroceden en el tiempo, sino son los hechos y situaciones, cumplidos o no, los que por imperativo legal cobran actualidad en la medida que ello sea posible para ser regulados por la ley nueva" 2 .

Por lo tanto, la retroactividad es una ficción legal en virtud de la cual una ley nueva pretende extender su aplicación temporal al ámbito regido por una norma anterior.

La regla general es que la ley se aplica a los actos celebrados y a los hechos acaecidos durante su vigencia, es decir, entre la fecha de su entrada en vigor y la fecha de su derogación. En consecuencia, una ley será retroactiva cuando se aplique a hechos o actos realizados con anterioridad a su entrada en vigencia. Sin embargo, el problema se presenta cuando los actos celebrados o los hechos acaecidos bajo la vigencia de una ley producen todos o algunos de sus efectos bajo el imperio de otra. Este problema supone que determinados actos y hechos jurídicos producen efectos que permanecen en el tiempo, pudiendo durante este intervalo cambiar la ley bajo la cual se celebró u ocurrió el acto o hecho que hizo nacer dichos efectos. Surge entonces la pregunta ¿qué ley debe aplicarse, la antigua o la nueva? ¿Si se aplica la ley nueva, es esta retroactiva?

La complejidad de la materia ha dado lugar a que comúnmente se consideren retroactivas tanto aquellas leyes que afectan hechos o actos realizados en el pasado, como aquellas que se aplican a los efectos de dichos hechos o actos, sea que estos hayan nacido durante la vigencia de la norma anterior y la sobrevivan, o que nazcan con posterioridad

${ }^{2}$ López Menudo (1982) p. 43. Énfasis en el original. 
a ella. En consecuencia, se hace necesario distinguir entre efecto retroactivo y efecto inmediato, y entre irretroactividad e intangibilidad.

\subsection{EFECTO RETROACTIVO Y EFECTO INMEDIATO}

El verdadero alcance del efecto retroactivo de las leyes fue definido por Roubier al establecer la distinción entre el efecto retroactivo y el efecto inmediato de las leyes.

Según Roubier, una ley tiene efecto retroactivo cuando alcanza con sus efectos al tiempo anterior a su entrada en vigor, es decir, afectando hechos ocurridos en el pasado. Una ley retroactiva puede decirse que "penetra en el dominio de la norma antigua", volviendo sobre el pasado. De esta manera, la retroactividad puede definirse como la prolongación de la aplicación de la ley a una fecha anterior a la de su entrada en vigor, como una ficción de preexistencia de la ley ${ }^{3}$.

Por el contrario, una ley tiene efecto inmediato cuando rige todas las situaciones existentes desde su entrada en vigor: la ley nueva no permite la subsistencia de la ley antigua, ni siquiera para las situaciones jurídicas nacidas en el tiempo en que esta última regía; en virtud del efecto inmediato los efectos de la ley antigua producidos después de la entrada en vigor de la nueva norma quedan sujetas a esta ${ }^{4}$.

Por lo tanto, solo una ley que intente aplicarse a los hechos acaecidos o a los actos ejecutados durante la vigencia de una ley anterior será retroactiva; por el contrario, si una nueva ley pretende aplicarse a los efectos de hechos o actos realizados en el pasado no tendrá efecto retroactivo, sino solo efecto inmediato.

Algunos autores contemporáneos han recogido esta distinción usando otra terminología, refiriéndose a distintos niveles de retroactividad según el grado de penetración de la nueva norma en el ámbito de la norma anterior. En este sentido, Suárez Collía reconoce la existencia de retroactividad en grado máximo o absoluta (la nueva norma se aplica en su totalidad a una relación jurídica nacida o incluso ejecutada al amparo de la legislación anterior, afectando tanto a la relación jurídica básica como a todos sus efectos); retroactividad en grado medio (la nueva ley se aplica a una relación o situación jurídica que tuvo su origen durante la vigencia de una ley ya derogada, pero se limita a regular las consecuencias nacidas o que hayan de ejecutarse a partir del momento de su entrada en vigor), y retroactividad en grado mínimo o atenuada (la nueva ley es aplicable exclusivamente a los efectos de la relación jurídica que nazcan con posterioridad a su entrada en vigor) ${ }^{5}$.

En virtud de las distinciones anteriores, solo son propiamente retroactivas aquellas leyes que incurren en la ficción de volver a regular hechos pasados, es decir, las leyes clasificadas como retroactivas por Roubier, o retroactivas en su grado máximo por los autores contemporáneos. Por el contrario, las leyes que pretenden afectar situaciones presentes cuyo régimen jurídico fue establecido por una ley anterior (leyes de efecto inmediato o retroactivas en grado medio o mínimo) no son propiamente retroactivas, ya que no pretenden cambiar la calificación jurídica de hechos pasados.

\footnotetext{
3 AlESSANDri y SOMARRIVA (1961) p. 175.

${ }^{4}$ ALESSANDri y SOMARRIVA (1961) p. 175.

5 SUÁrez COLlía (1994) pp. 70-75.
} 


\subsection{IRRETROACTIVIDAD E INTANGIBILIDAD}

En la aplicación temporal de la ley también es necesario distinguir entre irretroactividad e intangibilidad. Mientras el problema de la irretroactividad está orientado al pasado, el problema de la intangibilidad está orientado exclusivamente hacia el futuro. La irretroactividad dice relación con la prohibición de "trasladar" una norma hacia el pasado, extendiendo sus efectos a hechos anteriores a su vigencia. La intangibilidad, por su parte, se refiere a la inmutabilidad de las situaciones o los actos jurídicos creados bajo el imperio de una norma, los que a pesar de eventuales cambios en la normativa quedan regidos por las prescripciones de la norma antigua ${ }^{6}$.

Siguiendo la distinción entre efecto retroactivo y efecto inmediato, no es necesario que una norma tenga efecto retroactivo para afectar la intangibilidad de las situaciones jurídicas creadas bajo el amparo de otra norma. Por el contrario, es perfectamente posible que una norma de efecto inmediato afecte derechos adquiridos. En este sentido, Madariaga Gutiérrez sostiene que "una norma que se dicta para regir hacia el futuro de manera diferente las situaciones creadas antes de su vigencia $-y$ que se prolongan como derechos adquiridos con posterioridad a su promulgación o simple notificación- no es una norma de efectos retroactivos. El respeto a los derechos adquiridos cuyo dominio se extiende bajo la vigencia de la norma nueva será el problema de inmutabilidad de las situaciones creadas, mas no de retroactividad" 7 . Sin embargo, ha sido usual entre los autores confundir estos dos estadios conceptuales, ya que muchos han catalogado como retroactivas normas que rigen solo hacia el futuro cuando estas afectan derechos adquiridos por las personas en virtud de una ley anterior ${ }^{8}$.

En consecuencia, el problema de los derechos adquiridos es un problema de intangibilidad, no de retroactividad. En cuanto a su proyección hacia el futuro, tanto las normas propiamente retroactivas como las que no lo son pertenecen al campo de la intangibilidad. Mientras una ley propiamente retroactiva se introduce en el pasado para cambiar o anular los actos generadores de determinadas situaciones jurídicas, afectando en consecuencia los efectos de dichas situaciones, una ley de efecto inmediato las afecta directamente, dirigiéndose solo en contra de los efectos prolongados en el tiempo de

\footnotetext{
${ }^{6}$ Madariaga Gutiérrez (1965) pp. 116-117.

7 Madariaga Gutiérrez (1965) p. 117.

${ }^{8}$ Un ejemplo de esta confusión lo encontramos en las explicaciones de Claro Solar en relación con el efecto retroactivo o inmediato de las normas. Señala Claro Solar que "la ley no produce efecto retroactivo por el solo hecho de aplicarse a situaciones o relaciones anteriores, porque son únicamente consecuencias nuevas que gobierna por la circunstancia de realizarse bajo su imperio. Al contrario, será retroactiva cuando ataque derechos adquiridos si lo que había sido adquirido es quitado por ella y perdido para aquel que la tenía. En este sentido no es literalmente exacto decir que la ley solo pueda regir los hechos futuros que se producen sin relación con un hecho anterior, ella puede regir los hechos futuros que derivan o son la consecuencia de hechos pasados sin producir efecto retroactivo" (CLARO SOLAR, 1978, p. 61). Claro Solar está en lo correcto al señalar que una ley nueva puede afectar situaciones jurídicas creadas mediante una ley anterior, sin tener por ello efecto retroactivo. Sin embargo, confunde retroactividad e intangibilidad al afirmar que la nueva ley tendrá efecto retroactivo si su aplicación implica que derechos que habían sido adquiridos en virtud de la ley anterior serán quitados o menoscabados, ya que es perfectamente posible que una norma de efecto inmediato afecte derechos adquiridos en virtud de una norma anterior. El problema en este caso no es un problema de retroactividad de la norma nueva, sino de intangibilidad de los efectos producidos por la norma anterior.
} 
actos jurídicos o hechos ocurridos con anterioridad a su dictación. Ambas normas -la de efecto retroactivo y la de efecto inmediato- pueden afectar situaciones jurídicas creadas bajo el amparo de la norma anterior.

Por lo tanto, el verdadero problema de la aplicación temporal de la ley en el tiempo no pertenece al campo de la irretroactividad, sino al campo de la intangibilidad. Los juristas de antaño, con el objeto de otorgar certeza y continuidad a los actos realizados en conformidad a las leyes vigentes y a los efectos de dichos actos, erraron en el enfoque del problema: se centraron en su manifestación dinámica (la capacidad de una norma de accionar hacia el pasado) en vez de en su manifestación estática (la protección de las situaciones jurídicas creadas bajo la vigencia de una determinada norma). Sin embargo, el problema no es si acaso una ley puede o no accionar hacia el pasado; lo que se intenta proteger es la validez de los actos ejecutados legalmente bajo la vigencia de una norma, así como los efectos de dichos actos, frente a cambios posteriores en la legislación. En otras palabras, el interés jurídico protegido no es la irretroactividad per se, sino la intangibilidad de situaciones jurídicas creadas al amparo de normas vigentes.

En consecuencia, consideramos que es necesario replantear el problema de la irretroactividad bajo el prisma de la intangibilidad, poniendo énfasis en el respeto que merecen las situaciones jurídicas creadas válidamente bajo una legislación vigente en un momento determinado. Por lo tanto, el enfoque constitucional que proponemos se refiere más a una teoría de la intangibilidad que a una teoría de la irretroactividad. Sin embargo, considerando lo arraigado que se encuentra en nuestro sistema jurídico el concepto de irretroactividad y su conexión histórica con la teoría de los derechos adquiridos, nos referiremos a la irretroactividad en sentido amplio, incluyendo dentro de este término el concepto de intangibilidad.

\section{CONSAGRACIÓN HISTÓRICA DEL PRINCIPIO DE IRRETROACTIVIDAD EN EL DERECHO POSITIVO CHILENO}

Históricamente, se ha entendido que el principio de irretroactividad se encuentra consagrado en el Código Civil y la Ley sobre Efecto Retroactivo de las Leyes.

El Art. 9 del Código Civil establece "La ley puede solo disponer para lo futuro y no tendrá jamás efecto retroactivo". Este principio se encuentra desarrollado en la Ley sobre Efecto Retroactivo de las Leyes, donde se establecen los criterios para determinar el efecto retroactivo de las leyes y resolver los conflictos que resulten de la aplicación de leyes dictadas en distintas épocas.

La Ley sobre Efecto Retroactivo de las Leyes se basa en la doctrina clásica de los derechos adquiridos y de las meras expectativas. En efecto, el artículo 7 de esta ley establece que "las meras expectativas no forman derecho". Según Claro Solar, este artículo está reconociendo implícitamente la teoría de los derechos adquiridos, estableciendo que las leyes posteriores no pueden afectar los derechos ya adquiridos, es decir, a las facultades o aptitudes ya ejercidas; pero sí puede afectar las meras expectativas o simples esperanzas de adquirir no ejercidas?.

${ }^{9}$ Claro Solar (1978) p. 65. 
Dado el rango legal de las normas que lo consagran, el principio de irretroactividad es -al menos en materia civil- derogable por el legislador. Ello debilita profundamente la eficacia del principio, ya que como señala Claro Solar la retroactividad "queda confiada a la prudencia y tino del legislador, para el cual el principio de no retroactividad es un simple consejo, un precepto que moralmente está obligado a observar y que, sin embargo, puede desconocer y de hecho ha desconocido en diversas épocas" 10 .

No ocurre lo mismo en materia penal, ya que la Constitución establece en el Art. 19 No 3 inc. $7^{\circ}$ que "ningún delito se castigará con otra pena que la que señale una ley promulgada con anterioridad a su perpetración, a menos que una nueva ley favorezca al afectado". En consecuencia, en virtud del principio pro reo, en materia penal solo se admiten leyes retroactivas cuando favorezcan al afectado.

\section{HACIA UNA TEORÍA CONSTITUCIONAL DE LA IRRETROACTIVIDAD E INTANGIBILIDAD}

Como hemos adelantado, hoy en día no es posible limitar el estudio de los principios de irretroactividad de las normas y de intangibilidad de las situaciones jurídicas creadas a las leyes recién citadas. Actualmente es posible encontrar los fundamentos de una teoría constitucional de la irretroactividad e intangibilidad en los artículos $19 \mathrm{~N}^{\circ}$ 24 y $19 \mathrm{~N}^{\circ} 26$ de la Constitución Política. El Art. $19 \mathrm{~N}^{\circ} 24$ proporciona una base más sólida que la que ha existido hasta hoy para la teoría de derechos adquiridos, elevando a nivel constitucional la protección otorgada a los derechos por la vía de su incorporación al patrimonio de las personas. El Art. $19 \mathrm{~N}^{\circ} 26$, por su parte, sirve como fundamento de una teoría de la intangibilidad independiente del derecho de propiedad, otorgando estabilidad a las situaciones jurídicas creadas sin necesidad de ampararlas en el derecho de propiedad.

\subsection{El ART. $19 \mathrm{~N}^{\circ} 24$ DE la CONSTITUCiÓN POlítica: LA BÚSQUEda de la IRRETROACTIVIDAD POR LA VÍA DE LA PROPIETARIZACIÓN DE LOS DERECHOS}

El Art. $19 \mathrm{~N}^{\circ} 24$ constituye el punto de partida para una teoría constitucional de la irretroactividad, al elevar a nivel constitucional la teoría de los derechos adquiridos. El inciso primero de este artículo dispone que la Constitución asegura a todas las personas "el derecho de propiedad en sus diversas especies sobre toda clase de bienes corporales o incorporales." Al asegurar el derecho de propiedad sobre los bienes incorporales, este inciso se ha usado para justificar la práctica de la propietarización de los derechos, lo que a su vez constituye una base constitucional para afirmar la irretroactividad de las normas y la intangibilidad de las situaciones jurídicas creadas por dichas normas. De esta manera, la teoría de los derechos adquiridos ha sido llevada a su máxima expresión: si los derechos se adquieren, es decir, si se incorporan al patrimonio de una persona, entonces quedan resguardados por el manto protector del Art. $19 \mathrm{~N}^{\circ} 24$. En otras

10 Claro Solar (1978) p. 61. 
palabras, las normas se entienden "irretroactivas" y los derechos adquiridos en virtud de dichas normas se vuelven intangibles porque, al ser incorporados al patrimonio de una persona, gozan de la misma inviolabilidad de la que gozan los demás bienes de propiedad de esa persona, incluso frente a la acción del legislador.

El análisis del Art. $19 \mathrm{~N}^{\circ} 24$ como fuente de la irretroactividad y la intangibilidad requiere en primer lugar un examen de la práctica de la propietarización de los derechos, y luego un análisis del alcance de la intangibilidad que este artículo proporciona a los derechos que se propietarizan en el contexto de la aplicación temporal de la ley.

\subsubsection{La propietarización de los derechos}

\section{(a) Fundamentos legales de la propietarización de los derechos}

Como hemos señalado anteriormente, de un tiempo a esta parte se ha convertido en una práctica común en la doctrina y en la jurisprudencia chilena el "cosificar" los derechos, es decir, concebirlos como cosas susceptibles de ser incorporadas al patrimonio $y$, en consecuencia, de ser cauteladas por la garantía constitucional del derecho de propiedad. La falta de adecuada seguridad jurídica en el ejercicio de los derechos, en especial en lo referente a la acción del legislador, ha dado lugar a la necesidad de intentar proteger dichos derechos por la vía de su incorporación al patrimonio, convirtiéndoles en objetos del derecho de dominio.

Ya era posible vislumbrar este mecanismo desde la Constitución de 1925. Según Alessandri y Somarriva, bajo esta carta fundamental era posible limitar la facultad del legislador de dictar leyes retroactivas respecto del derecho de propiedad. En efecto, el Art. $10 \mathrm{~N}^{\circ} 10$ de dicha Constitución aseguraba a todos los habitantes de la República "la inviolabilidad de todas las propiedades, sin distinción alguna. Nadie puede ser privado de la de su dominio, ni de una parte de ella, o del derecho que a ella tuviere, sino en virtud de una sentencia judicial o de expropiación por razón de utilidad pública, calificada por una ley". Para estos autores, en virtud de esta norma cualquier ley que atentara contra el derecho de propiedad constituido regularmente bajo el imperio de otra ley sería inconstitucional. Por lo tanto, el legislador no podía dictar leyes retroactivas con respecto al derecho de propiedad ${ }^{11}$.

Sin embargo, también era posible dar al Art. $10 \mathrm{~N}^{\circ} 10$ de la Constitución de 1925 una interpretación más amplia, concibiéndolo no solo como un límite a la retroactividad respecto del derecho de propiedad (en cuanto derecho real sobre una cosa corporal), sino como un límite a la retroactividad respecto de todos los derechos que pudieran ser objeto de dicho derecho de propiedad. En efecto, nuestra legislación positiva dispone que sobre los derechos existe una "especie de propiedad". El Art. 565 del Código Civil establece que "los bienes consisten en cosas corporales e incorporales", señalando que las corporales son aquellas que tienen existencia real y pueden ser percibidas por los sentidos, mientras que las cosas incorporales son las que consisten en meros derechos. Más

11 Alessandri y Somarriva (1961) pp. 176-177. 
adelante, el Art. 582 define el dominio (llamado también propiedad) como "el derecho real en una cosa corporal, para gozar y disponer de ella arbitrariamente; no siendo contra ley o contra derecho ajeno". A su vez, el Art. 583 dispone que "sobre las cosas incorporales existe una especie de propiedad", mientras que el Art. 584 establece que "las producciones del talento y del ingenio son una propiedad de sus autores". Por lo tanto, incluso bajo la Constitución de 1925 era posible concebir la propiedad sobre los derechos y, en consecuencia, su intangibilidad frente a leyes retroactivas.

Esta tendencia a la propietarización de los derechos se ha desarrollado aún más después de la Constitución de 1980, ya que nuestra actual carta fundamental garantiza expresamente la propiedad sobre las cosas incorporales. Ya que el derecho de propiedad está amparado por el recurso de protección (Art. 20 de la Constitución Política), amparo del que gozan solo algunos de los demás derechos garantizados en el Art. 19 de la de la Constitución Política, resulta conveniente extender su protección a los demás derechos por la vía de su propietarización.

La doctrina chilena, casi sin excepciones, ha interpretado las disposiciones recién citadas como fundamento de la tesis de la propietarización de los derechos. En este sentido, Corral Talciani afirma que "el Código Civil admite, sin lugar a dudas, la conclusión de que el sujeto activo de un derecho real o personal es, a la vez, titular de un derecho real de propiedad que recae sobre ese mismo derecho o crédito, el que es considerado por la ley como 'cosa', si bien incorporal. El acreedor se convierte así en 'dueño' de su crédito, y el usufructuario en propietario de su derecho de usufructo"12.

\section{(b) Criticas a la propietarización de los derechos}

A pesar de su generalizada aceptación por la doctrina, algunos autores critican duramente la tendencia a propietarizar los derechos.

Vergara Blanco considera que, si bien nuestro ordenamiento jurídico permite expresamente la propietarización de los derechos, esta práctica está produciendo una desfiguración del derecho de propiedad. En opinión de este autor, cada derecho debiera tener protección en sí, como derecho independiente, sin que sea necesario recurrir al derecho de propiedad para darle debida protección. El problema, según Vergara Blanco, "estriba en que el ordenamiento legal chileno no ha reconocido validez (y seguridad jurídica, pues de eso se trata) a estos derechos como tales, sino siempre a través de una desnaturalización: considerándolos o vinculándolos a la propiedad"13.

Vergara Blanco pronostica que si seguimos por este camino llegaremos al sinsentido jurídico de que el único derecho que realmente existe es el de propiedad, ya que todos los demás derechos son objeto de dicho derecho de propiedad y quedan protegidos por la garantía constitucional que protege a este "supraderecho". Según este autor, la exageración de esta práctica llevará finalmente a la desnaturalización del derecho de propiedad, ya que si bien produce los efectos prácticos queridos por los constituyentes (la protección de los derechos), esta práctica está conduciendo a la institución de la

12 Corral Talciani (1996) p. 14.

13 Vergara Blanco (1991-1992) p. 281. Ver también Vergara Blanco (1990) P. 492. 
propiedad a una crisis dogmática al pretender que este cubra todas las titularidades y todas las posiciones jurídicas, sea respecto de cosas o personas ${ }^{14}$.

Por su parte, Guzmán Brito afirma que la doctrina de la propietarización de los derechos no encuentra sustento en nuestro ordenamiento positivo. Según este autor, una interpretación literal y sistemática de los artículos 565, 582, 583 y 584 del Código Civil no permite concluir que los titulares de un derecho tengan un derecho de dominio sobre ese derecho. Según Guzmán Brito, la propiedad sobre las cosas corporales (o "dominio") es radicalmente distinta de la propiedad sobre las cosas incorporales, así como de la propiedad sobre las producciones del talento o ingenio. Para Guzmán Brito, estas tres propiedades serían todas especies de un género superior de propiedad, cuya esencia radicaría en el hecho de constituir una titularidad exclusiva sobre una cosa, sea esta corporal, incorporal, o una producción del talento ${ }^{15}$.

Guzmán Brito llega a la conclusión que "la propiedad de las cosas incorporales referida por el Art. 583 del Código Civil no es una especie del dominio o propiedad de las cosas corporales definido por el Art. 582; es decir, no está comprendida ahí, y constituye una especie distinta y separada, cuyo género común es la cualidad de ser propio, que por esto llamamos también 'propiedad" 16 . Esta propiedad específica sobre las cosas incorporales sería solo un dominio impropio o 'cuasi dominio', ya que "la especie de propiedad sobre las cosas incorporales a que se refiere el Art. 583 del Código Civil no es ella misma un derecho real ni, por ende, una cosa incorporal, mas solo un atributo abstracto que ofrecen estas cosas, igual que el dominio, de ser propias de alguien" ${ }^{17}$.

La propietarización de los derechos es criticada no solo en relación con sus fundamentos, sino también en relación con el objeto de dicha propietarización. La tendencia actual en la jurisprudencia es otorgarle protección por la vía del derecho de propiedad a innumerables situaciones jurídicas o titularidades que no constituyen propiamente derechos. Vergara Blanco cita varios ejemplos: 'propiedad sobre el empleo', 'propiedad sobre una concesión', 'propiedad sobre la calidad de estudiante universitario', 'propiedad sobre beneficios previsionales', etc. Según este autor, sería más apropiado otorgarle protección directa a esas titularidades o posiciones jurídicas en su calidad de tales, en vez de convertirlas en objeto del derecho de propiedad ${ }^{18}$.

Por su parte, Guzmán Brito desaprueba la práctica de propietarizar situaciones jurídicas que no constituyen propiamente cosas incorporales. En este sentido, señala que "los conceptos de 'bien' y de 'cosa corporal' e 'incorporal' tienen en nuestro derecho un carácter muy definido y técnico (...). Los bienes o son cosas corporales en el sentido del Art. 562 inc. 2 [del Código Civil], o son cosas incorporales en el del Art. 562 inc. 3; a su vez, estas últimas son siempre derechos, los cuales pueden ser reales o personales. En consecuencia, para que haya cosa incorporal menester es que exista un derecho de una u otra clase" 19 .

14 VERGARA BLANCO (1991-1992) p. 291.

15 GUZMÁN BRITO (1995) pp. 134-142.

16 GUZMÁN BRITO (1995) p. 138.

17 GUZMÁN BRITO (1995) p. 143.

18 VERGARA BLANCO (1991-1992) pp. 289-291.

19 GUZMÁN BRITO (1995) p. 99. 
Determinar cuáles son los derechos reales es fácil, ya que estos son solo aquellos que la ley declara tales. No ocurre lo mismo con los derechos personales, ya que estos son todos aquellos que nazcan de las fuentes de las obligaciones, ya sea del contrato, el cuasicontrato, el delito, el cuasidelito o la ley. El problema se produce respecto de la ley, ya que, según Guzmán Brito, "el derecho contemporáneo ha hecho caer en crisis al sistema clásico de fuentes, porque el papel más bien modesto que en él ocupaba la ley como causa de derechos personales, vino ahora a ser sustituido por una posición sobresaliente de la misma en tal función", surgiendo así una multitud de "derechos subjetivos legales" 20 . En opinión de Guzmán Brito, algunos de estos derechos subjetivos legales constituyen verdaderos derechos, tales como aquellos de naturaleza laboral o previsional. Sin embargo, no ocurre lo mismo con los llamados "derechos de la persona", ya que en la mayoría de los casos se presenta el problema de la indeterminación de la prestación correlativa, fruto de la ambigüedad de las fórmulas con que son descritos en las constituciones y tratados internacionales, o incluso de su carácter extrajurídico, ya que contienen generalmente "declaraciones programáticas de mejoramiento moral, social, económico y cultural que por su propia naturaleza no son aptas para constituir la materia de una prestación exigible en derecho por cada individuo, aunque eventualmente puedan dar sustancia a programas de acción política, sostenibles por los grupos y partidos o ejecutables por los gobiernos" 21 .

Esta práctica ha hecho surgir en la actualidad un fenómeno sociológico que Guzmán Brito denomina "inflación de los derechos", consistente en "mirar como nuevos derechos innatos los que en verdad no son más que pretensiones, aspiraciones e intereses subjetivos y socializados de ventajas", los que a pesar de ser "intereses sociales políticamente defendibles", no son "derechos judicialmente reclamables"22. Esta tendencia se ha desarrollado aún más después de la Constitución de 1980, ya que dado el amparo que otorga el recurso de protección al derecho se propiedad, resulta conveniente extender su protección a otras pretensiones subjetivas, convirtiéndolas en bienes incorporales sobre los que su titular ejerce un derecho de propiedad amparable por el recurso ${ }^{23}$.

Guzmán Brito rechaza esta tendencia a inflar los derechos, señalando que "no hay 'bien' en donde no hay cosa corporal, incorporal o intelectual, ni cosa incorporal en donde no hay un derecho real o personal. A su vez, no hay derecho real si no está tipificado por ley; y no hay derecho personal en donde no hay deuda de dar, hacer o no hacer a cargo de un sujeto pasivo o deudor determinado, aunque por sumatoria resulte que todos lo son, la cual provenga (...) de un contrato o cuasicontrato, de un delito o cuasidelito o de la ley". La ley, en consecuencia, puede efectivamente atribuir ventajas subjetivas, incluso no patrimoniales, pero estas no serán derechos personales no se señala explícita o implícitamente un deudor determinado que deba cumplir la correspondiente prestación ${ }^{24}$.

${ }^{20}$ GUZMÁN BRITO (1995) p. 99.

21 GUZMÁN BRITO (1995) p. 100.

22 GUZMÁN BRITO (1995) pp. 100-101.

23 GUZMÁN BRITO (1995) pp. 101-102.

${ }^{24}$ GUZMÁN BRito (1995) pp. 102-103. 
Habiendo definido el verdadero alcance del concepto de cosa incorporal, Guzmán Brito mantiene que no todas las cosas incorporales están protegidas por garantía constitucional de la propiedad. Guzmán Brito observa que el Art. $19 \mathrm{~N}^{\circ} 24$ garantiza el derecho de propiedad en sus diversas especies sobre toda clase de bienes corporales o incorporales. En este sentido, Guzmán Brito señala que, si bien todos los bienes son cosas, no todas las cosas son bienes ${ }^{25}$. En efecto, Guzmán Brito entiende que "entre las cosas y los bienes hay una relación de género a especie; bienes son las cosas que, prestando una utilidad para el hombre, son susceptibles de apropiación"26.

En virtud de lo anterior, Guzmán Brito considera que el verdadero sentido del uso del término bien en la Constitución Política es restringir el alcance de la garantía a aquellas cosas que tengan un valor patrimonial y sean susceptibles de apropiación. Para Guzmán Brito, la consecuencia práctica de esta conclusión es dejar todo derecho que no sea un "bien" (es decir, todo derecho que no sea de carácter patrimonial) fuera del amparo del recurso de protección, ya que este solo cautela el derecho de propiedad sobre bienes corporales e incorporales ${ }^{27}$.

La tesis de Guzmán Brito no ha encontrado gran apoyo en la jurisprudencia, ya que son innumerables los casos en que se han interpuesto recursos de protección fundados en la propiedad sobre un derecho "de la persona", muchos de los cuales han sido acogidos por nuestros tribunales ${ }^{28}$.

\section{(c) La propietarización ante la Comisión de Estudio para la Nueva Constitución (“C.E.N.C.”)}

A pesar de las críticas anteriores, cabe hacer presente que la historia fidedigna del establecimiento de la Constitución de 1980 indica que la C.E.N.C. apoyaba -o al menos toleraba- la práctica de la propietarización.

En efecto, la C.E.N.C. dejó en claro que la referencia a las cosas incorporales tenía como objeto incluir todo tipo de derechos y situaciones jurídicas en la garantía constitucional de la propiedad. En palabras de Silva Bascuñán “(...) se concibe el derecho de propiedad como comprensivo de todo beneficio de carácter patrimonial, ya sea el derecho real de dominio sobre cosas muebles e inmuebles, sobre derechos reales y personales, sobre cosas corporales e incorporales y sobre cualquier tipo de beneficios patrimoniales. (...) Estas normas se refieren a todos los estatutos de los beneficios patrimoniales, cualquiera sea su índole y, respecto de todos ellos, afirma la necesidad de respetar su esencia" 29 .

\footnotetext{
25 GUZMÁN BRITO (1995) p. 241.

26 GUZMÁN BRITO (1995) p. 241.

27 GUZMÁN BRITO (1995) p. 243.

28 A modo de ejemplo, la jurisprudencia ha afirmado la existencia de la propiedad sobre los derechos a los beneficios de seguridad social (ver Torres Zamora, Claudia con Superintendente de Seguridad Social), y sobre la calidad de alumno (ver García Schiele, Claudio, con Vicerrector Académico de la Universidad Austral de Chile).

${ }^{29}$ C.E.N.C., Actas Oficiales, Sesión No 155.
} 
En el mismo sentido, Diez afirmó que la garantía del Art. 19 No 24 “(...) no se está refiriendo solo al derecho de dominio sobre cosas corporales e incorporales, sino a lo que es el derecho de propiedad en toda su amplitud; al derecho que tiene una persona sobre su previsión, que tampoco puede ser afectado en su esencia; a todo tipo de derechos de propiedad, no solo a la propiedad sobre las cosas corporales. (...) Es tan grande la gama de los derechos de propiedad, que comprende desde el que de alguna manera tiene el trabajador sobre su empleo, hasta el del dueño de un bien raíz; desde el derecho de propiedad de una jubilación, hasta el que tiene el derecho, usando una expresión que quizás no sea feliz, a la propiedad de la expectativa de su previsión" 30 .

Lo anterior nos lleva a concluir que para la C.E.N.C. el término "bienes incorporales" tenía como objeto cubrir todo tipo de derechos y situaciones jurídicas con el manto protector del derecho de propiedad. Por lo tanto, aun si aceptáramos la teoría de Guzmán Brito en el sentido de reconocer que existe un género superior de propiedad, y que los artículos 582, 583 y 584 del Código Civil establecen solo especies de ese género, no parece posible afirmar que dichas especies de propiedad hayan quedado fuera de la garantía constitucional del artículo 19 No 24. Por el contrario: puede que los constituyentes de 1980 hayan llegado a una conclusión similar a la de Guzmán Brito, estableciendo en el artículo 19 No 24 una garantía sobre el género propiedad, es decir, sobre la propiedad concebida como titularidad exclusiva. Tanto las palabras de Silva Bascuñán, al referirse a los distintos estatutos de los beneficios patrimoniales ${ }^{31}$, así como las de Diez, al señalar que Art. $19 \mathrm{~N}^{\circ} 24$ se refiere al "derecho de propiedad en toda su amplitud"32, permiten considerar la posibilidad de que la C.E.N.C. haya querido garantizar un género superior de titularidad.

4.1.2 La intangibilidad que proporciona a los derechos el Art. $19 N^{\circ} 24$ en el contexto de la aplicación temporal de la ley

La consecuencia práctica de la tendencia a propietarizar los derechos ha sido otorgar a toda clase de derechos y situaciones jurídicas la intangibilidad de que goza el derecho de propiedad bajo el Art. $19 \mathrm{~N}^{\circ} 24$ de la Constitución Política. En el contexto de la aplicación temporal de la ley, esta intangibilidad implica que un derecho (o titularidad sobre una situación jurídica) adquirido bajo una determinada ley e incorporado al patrimonio de su titular por la vía de la propietarización no puede ser modificado por una ley posterior ${ }^{33}$.

30 C.E.N.C., Actas Oficiales, Sesión No 155.

31 C.E.N.C., Actas Oficiales, Sesión No 155.

32 C.E.N.C., Actas Oficiales, Sesión No 155.

33 A modo de ejemplo, ver De la Cerda Tapia, Fernando y otro con servicio Agrícola y Ganadero. El extracto de doctrina agregado por la Revista de Derecho y Jurisprudencia señala que "habiendo cumplido los recurrentes con las exigencias impuestas por la ley para obtener determinados derechos, han adquirido un derecho incorporal de propiedad sobre ellos, derecho que la Constitución reconoce y ampara en su artículo $19 \mathrm{~N}^{\circ} 24$. Una nueva ley que se pretende abrogatoria de una anterior que concedía un beneficio ya ingresado al patrimonio de los recurrentes, no es tal, porque de admitirse esos efectos abrogatorios estos lesionarían el derecho incorporal de propiedad señalado, por cuyo motivo resulta inaplicable ella en el juicio civil donde se persigue el cobro de derechos impagos aún por la autoridad". (R.D.J. (1984) pp. 16-17). 
Sin embargo, la intangibilidad que proporciona el Art. $19 \mathrm{~N}^{\circ} 24$ no es absoluta. Los incisos segundo y tercero del artículo citado establecen las condiciones bajo las cuales el derecho de propiedad puede ser restringido o incluso privado.

\section{(a) Restricciones al derecho de propiedad}

El inciso segundo del Art. $19 \mathrm{~N}^{\circ} 24$ establece que "[S]ólo la ley puede establecer el modo de adquirir la propiedad, de usar gozar y disponer de ella y las limitaciones y obligaciones que deriven de su función social. Esta comprende cuanto exijan los intereses generales de la Nación, la seguridad nacional, la utilidad y la salubridad públicas y la conservación del patrimonio ambiental".

Tanto la limitación como la obligación son formas de restricción. Sin embargo, la limitación generalmente constituye una restricción de carácter negativo, que implica una obligación de no hacer algo, o de poder hacerlo en menor medida que antes de haberse impuesto la limitación. El término obligación, por el contrario, tiene en este contexto usualmente un carácter positivo, que implica un deber de hacer algo que antes no se estaba obligado a hacer.

De acuerdo al inciso segundo del Art. $19 \mathrm{~N}^{\circ}$ 24, el derecho de propiedad puede ser restringido solo por la acción del legislador. Según Evans de la Cuadra, esta referencia a la ley tiene por objeto cuidar que ninguna autoridad de inferior jerarquía al legislador regule la forma de usar, gozar y disponer del dominio, y no constituye una autorización al legislador para prohibir o vulnerar las facultades del dueño, salvo que se trate de imponer una obligación o limitación lícita al derecho de propiedad ${ }^{34}$. En efecto, quedó constancia en las Actas de la C.E.N.C. que "la regulación, complementación o interpretación de las garantías que asegura la Constitución corresponden exclusivamente al ámbito de la ley”, y que "ni el poder administrador ni ningún otro poder público pueden atribuirse la facultad de regular, complementar o interpretar las garantías que asegura el texto constitucional" 35 .

Sin embargo, se discute en la doctrina el alcance de esta reserva legal, planteándose al respecto una tesis 'extensiva' y otra 'restrictiva', según la extensión que otorgan a la reserva legal ${ }^{36}$. Los seguidores de la tesis extensiva sostienen que la ley debe desarrollar al máximo las regulaciones que le competan respecto de los derechos fundamentales, correspondiendo al reglamento su sola ejecución y no el establecimiento de nuevas regulaciones en reemplazo de la ley ${ }^{37}$. De este modo, estaría prohibida cualquier regulación

\footnotetext{
${ }^{34}$ EVANS DE LA CUADRA (1986) t. 2, p. 279.

35 C.E.N.C., Actas Oficiales, Sesión N² 212.

36 RAJEVIC MOSLER (1996) pp. 75-86.

37 En este sentido, la disidencia a la sentencia del Tribunal Constitucional recaída sobre el proyecto de ley de Bases Generales del Medio Ambiente señala que "es sabido que la regulación de los derechos fundamentales ha sido entregada -excepción hecha del derecho de reunión...- a la reserva del legislador, en cuanto es este el órgano estatal competente para dictar normas que permitan su más adecuada realización por sus titulares ... Pero hay más: a fin de asegurar efectivamente que sea el legislador quien determine esa regulación, le prohíbe expresamente que delegue atribuciones legislativas en tal materia, de tal manera que jamás puede el Presidente de la República -en tal caso a través de D.F.L.- intervenir la regulación del ejercicio de los derechos fundamentales (Art. 61.2, C.P. R.)". (Sentencia del Tribunal Constitucional sobre el proyecto de ley sobre "Bases Generales del Medio Ambiente, Rol No 185 (1994), disidencia del Ministro Jordán y del Abogado Integrante Sr. Eduardo Soto Kloss, fs. 73 vta.).
} 
reglamentaria de los derechos fundamentales, sea por la vía de la potestad reglamentaria autónoma o la potestad reglamentaria de ejecución, siendo inconstitucional cualquier ley que delegue dicha regulación al reglamento.

Los seguidores de la tesis restrictiva, por el contrario, afirman que la ley puede delegar la regulación de los derechos fundamentales en la potestad reglamentaria de ejecución. En este sentido, Reyes Riveros sostiene que la ley solo debe establecer los principios rectores de la normativa que regula el ejercicio de los derechos inherentes a la persona, debiendo la potestad reglamentaria desarrollar las se las normas básicas legales ${ }^{38}$.

En todo caso, la autorización dada al legislador (o a la autoridad administrativa, para los seguidores de la tesis restrictiva) para imponer limitaciones u obligaciones al dominio queda reducida solo a su función social. Bajo la Constitución de 1980 la función social de la propiedad comprende solamente (siendo taxativa la enumeración) los siguientes bienes jurídicos: los intereses generales de la nación, la seguridad nacional, la utilidad y salubridad públicas y la conservación del patrimonio ambiental.

\section{(b) Privación del derecho de propiedad}

El inciso tercero del Art. $19 \mathrm{~N}^{\circ} 24$ establece la obligación para el Estado de expropiar e indemnizar cualquier privación del derecho de propiedad, disponiendo que "[n] adie puede, en caso alguno, ser privado de su propiedad, del bien sobre que recae o de alguno de los atributos o facultades esenciales del dominio, sino en virtud de ley general o especial que autorice la expropiación por causa de utilidad pública o de interés nacional, calificada por el legislador. El expropiado podrá reclamar de la legalidad del acto expropiatorio ante los tribunales ordinarios y tendrá siempre derecho a indemnización por el daño patrimonial efectivamente causado, la que se fijará de común acuerdo o en sentencia dictada conforme a derecho por dichos tribunales."

Esta obligación impuesta al Estado de expropiar en caso de privaciones al dominio (junto con su correspondiente indemnización) se aplica tanto si la privación afecta:

(i) el derecho de propiedad mismo, es decir, la relación jurídica entre el titular y el bien;

(ii) el bien en que recae, es decir, la materialidad del objeto sobre el cual el titular ejerce su derecho de dominio, o

(iii) alguno de sus atributos y facultades esenciales, es decir, el contenido efectivo del derecho de dominio.

La expropiación solo puede ser impuesta por ley, sea esta general o especial, y por razones de utilidad pública calificada por el legislador. En todo caso, el expropiado tiene el derecho de reclamar de la legalidad de la expropiación ante los tribunales.

La obligación del Estado de indemnizar se refiere únicamente al daño patrimonial efectivamente causado. El monto de dicha indemnización será determinado de común acuerdo por las partes, o por los tribunales.

38 ReYes Riveros (1993) p. 83. 


\section{(c) El deslinde entre restricción y privación}

El deslinde entre privación y restricción es teóricamente claro, pero a veces difícil de reconocer en la práctica. El término privar supone despojar a uno de una cosa que poseía. Por el contrario, restringir implica reducir o aminorar algo que se tiene o posee, de manera de poder ejercer las facultades que esa tenencia o posesión implican pero de manera menor a su amplitud o extensión original ${ }^{39}$. El problema se produce cuando la restricción es de tal magnitud que, a pesar de no producir un despojo formal del derecho de propiedad, afecta algunos de sus atributos o facultades esenciales de manera de vaciar el derecho de su contenido efectivo. La importancia de distinguir ambos conceptos radica en que la privación da derecho a indemnización; no así la restricción (ya sea en forma de limitación u obligación).

El problema se planteó en la C.E.N.C., señalando Guzmán que si se usaba solo el término "privado" podría entenderse "que mientras quede un atisbo o residuo de facultad al propietario, este no ha sido privado, sino menoscabado solamente". Para Guzmán, debía entenderse que la palabra "privado" incluía el concepto de "menoscabo sustancial", de manera que si se llegase a limitar una facultad "en una parte que exceda de la mitad o se acerque a la mitad, evento en que no puede hablarse de privación en el sentido integral de la palabra (...) se entendería que debiera quedar el órgano jurisdiccional facultado para apreciar en qué grado y en qué momento ese menoscabo llega a tener un carácter tan marcado o sustancial que pueda ser asemejado a la privación" ${ }^{40}$. Como ejemplo, señalaba Guzmán que "es evidente que si se fuerza a una persona a enajenar todo o parte de su propiedad, en términos y condiciones en que no podrá encontrar compradores por su verdadero valor comercial, se está frente a una privación del derecho de dominio" ${ }^{41}$.

Para Guzmán, la determinación del límite entre limitación y privación debía quedar entregada al juez, de manera que "si el menoscabo es sustancial y se acerca más a la privación que a la limitación, pueda entenderse o configurarse por este órgano que ha existido privación y, por lo tanto, exigirse una ley expropiatoria”².

El tema se debatió largamente en la C.E.N.C., quedando constancia que una supuesta limitación u obligación implicaría privación siempre que afectara la esencia del derecho de propiedad. En palabras de Evans de la Cuadra, "ninguna limitación u obligación impuesta por la ley a la propiedad privada produce para el afectado derecho a indemnización, pero esa garantía no puede, en caso alguno, afectar la esencia del derecho con medidas como: privar, o reducir gravemente, del derecho de uso, del de goce, del de disposición; restringir alguno de ellos con medidas de tal envergadura que el dueño pase a ser un dependiente de la autoridad pública; privar de la capacidad de administrar, llegar a efectiva privación del dominio o de alguno de sus tres atributos, como consecuencia de actos de autoridad no aceptados ni consentidos por los propietarios y que no están comprendidos en los bienes jurídicos que conforman la función social del dominio" 43 .

\footnotetext{
39 Soto Kloss (1996) p. 92-93.

40 C.E.N.C., Actas Oficiales, Sesión No 161.

${ }^{41}$ C.E.N.C., Actas Oficiales, Sesión No 161.

42 C.E.N.C., Actas Oficiales, Sesión No 161.

43 Evans DE LA CUADra (1999) t. 3, p. 235. Énfasis en el original.
} 
De la misma manera, Cea Egaña sostiene que limitar u obligar en ningún caso equivale a privar -total o parcialmente- del dominio legalmente adquirido. El supuesto obvio de las limitaciones u obligaciones impuestas es que con ellas no es posible privar al titular de su propiedad, del bien sobre que recae o de alguno de los atributos o facultades esenciales del dominio, ya sea directa o indirectamente, retroactivamente o hacia futuro ${ }^{44}$.

El Tribunal Constitucional ha adherido a la misma postura, señalado que "las limitaciones suponen el establecimiento de determinadas cargas al ejercicio de un derecho, dejándolo subsistente en sus facultades esenciales" ${ }^{45}$.

4.1.3 Conclusiones sobre el Art. $19 N^{\circ} 24$ como fundamento de los principios de irretroactividad e intangibilidad

El análisis de las normas anteriores nos permite concluir que el Art. $19 \mathrm{~N}^{\circ} 24$ sirve de fundamento constitucional para el principio de irretroactividad y la teoría de los derechos adquiridos, por la vía de extender a dichos derechos la intangibilidad de que goza el derecho de propiedad. Sin embargo, esta intangibilidad no es absoluta, ya que el Art. $19 \mathrm{~N}^{\circ} 24$ permite expresamente que leyes posteriores impongan limitaciones u obligaciones a la propiedad que se ejerza sobre derechos incorporados al patrimonio de sus titulares, siempre que estas limitaciones u obligaciones deriven de la función social de la propiedad.

Asimismo, el Art. $19 \mathrm{~N}^{\circ} 24$ permite incluso la privación total un derecho adquirido por la vía de la expropiación, mediando indemnización por el daño efectivamente causado. Esta expropiación será procedente cuando la ley posterior afecte alguna de las facultades esenciales del derecho afectado, aun si no ha existido privación en sentido formal. Cabe destacar que en este caso no es necesario que la privación derive de la función social de la propiedad: para que proceda la expropiación basta que sea por causa de utilidad pública calificada por el legislador.

Como hemos señalado anteriormente, estas restricciones o privaciones al derecho de propiedad pueden derivar de leyes de efecto propiamente retroactivo (lo que ocurrirá cuando estas pretendan regular hechos acaecidos en el pasado) o de leyes de efecto inmediato (cuando dichas leyes afecten únicamente los efectos futuros de hechos ocurridos en el pasado).

\subsection{LA BÚsQUEDA DiReCTA DE LA IRRETROACTIVIDAD: EL ART. $19 \mathrm{~N}^{\circ} 26$ DE LA CONSTITUCIÓN DE 1980}

La Constitución de 1980 hace una importante innovación al otorgar protección independiente a los derechos reconocidos por la Constitución, es decir, concederles protección por su calidad de derechos públicos subjetivos, y no por ser "cosas" del dominio de sus titulares. En efecto, el Art. 19 No 26 de la Constitución de 1980 establece que la Constitución asegura a todas las personas:

${ }^{44}$ CeA Egaña (1988) p. 193.

45 Sentencia del Tribunal Constitucional sobre la constitucionalidad del Decreto Supremo $N^{\circ} 1 / 96$ del Ministerio de Bienes Nacionales, Rol N² 245-246 (1996). 
"La seguridad de que los preceptos legales que por mandato de la Constitución regulen o complementen las garantías que esta establece o que las limiten en los casos que ella autoriza, no podrán afectar los derechos en su esencia, ni imponer condiciones, tributos o requisitos que impidan su libre ejercicio.

Se exceptúan las normas relativas a los estados de excepción constitucional y demás que la propia Constitución contempla”.

En nuestra opinión, este artículo podría constituir el fundamento de una nueva teoría sobre la irretroactividad e intangibilidad, ya que al garantizar que la ley no podrá afectar en su esencia los derechos que ella establece ni impedir su libre ejercicio, la Constitución está otorgando una intangibilidad directa a dichos derechos frente la acción posterior del legislador. A diferencia del artículo $19 \mathrm{~N}^{\circ} 24$, la intangibilidad que otorga el artículo $19 \mathrm{~N}^{\circ} 26$ no deriva de una propietarización de los derechos, sino que se confiere a determinados derechos por el hecho de ser tales.

El examen del Art. $19 \mathrm{~N}^{\circ} 26$ como fuente de la irretroactividad y la intangibilidad requiere un análisis del bien jurídico protegido (la esencia de los derechos constitucionales y su libre ejercicio) y de las características de la protección que este artículo establece. Pero antes de entrar de lleno al contenido del Art. $19 \mathrm{~N}^{\circ} 26$, es necesario determinar como cuestión preliminar su aplicación real en nuestro ordenamiento jurídico.

\subsubsection{Aplicación real de la garantía de la esencia de los derechos}

Antes de analizar el contenido del artículo 19 No 26, es necesario determinar si es una norma que tiene aplicación directa en nuestro ordenamiento. En otras palabras, corresponde establecer si es una norma meramente programática o si su cumplimiento es exigible por la fuerza. Esto es especialmente importante si consideramos que el Art. 19 $\mathrm{N}^{\circ} 26$ no se encuentra amparado por el recurso de protección que establece el Art. 20 de la Constitución Política.

Gran parte de la doctrina alemana sostiene que el artículo 19.2 de su Constitución, análogo a nuestro artículo 19 No 26, tiene un significado meramente retórico y no protege nada que no estuviese ya protegido. La doctrina española adopta la misma postura, señalando que estas disposiciones no son sino un recordatorio para los derechos fundamentales de algo que es común a todos los preceptos constitucionales. La doctrina española va incluso más allá al señalar que, a pesar de que la garantía del contenido esencial de los derechos fundamentales persigue el robustecimiento de los mismos, el resultado es precisamente lo contrario: debilitar los derechos fundamentales. En efecto, "siendo innecesaria la norma (por meramente retórica) atribuye al legislador un poder para limitar los derechos fundamentales que de otro modo carecería" 46.

En opinión de Linazasoro Campos, esta postura debe ser rechazada por ser contraria a las más elementales normas de interpretación constitucional. Según este autor, otorgarle un simple valor retórico al Art. 19 No 26 privaría de validez normativa y eficacia a la disposición ${ }^{47}$.

\footnotetext{
${ }^{46}$ LiNAZASORO CAMPOS (1996) p. 54.
}

${ }^{47}$ Linazasoro Campos (1996) p. 55. 
Por el contrario, es posible afirmar que el Art. 19 No 26 tiene aplicación real en nuestro ordenamiento en al menos tres contextos. En primer lugar, se trata de un mandato al legislador en el cual la Constitución Política le prohíbe violar el núcleo de los derechos que la Constitución establece. En segundo lugar, el artículo $19 \mathrm{~N}^{\circ} 26$ debe ser considerado como una herramienta del control de la constitucionalidad de las leyes, tanto a priori como a posteriori, debiendo aplicarse tanto por el mismo legislador (al decidir si los límites que pretende imponer al derecho violan o no su núcleo esencial), como por el Tribunal Constitucional o la Corte Suprema, al determinar si una determinada ley o proyecto de ley han respetado la esencia de los derechos fundamentales. Finalmente, este artículo constituye una norma básica de interpretación de la ley, debiendo el juez, al interpretar la ley para el caso concreto, analizar la ley bajo el supuesto que el legislador no ha vulnerado la esencia de los derechos fundamentales, es decir, interpretando la ley de manera tal que se respete la esencia de los derechos fundamentales ${ }^{48}$.

En consecuencia, consideramos que la violación por parte de la ley al Art. $19 \mathrm{~N}^{\circ}$ 26 permite al afectado alegar la inaplicabilidad de la ley infractora mediante la interposición del recurso de inaplicabilidad que consagra el Art. 80 de la Constitución Política.

En virtud de lo anterior, consideramos que al garantizar la inviolabilidad de la esencia de los derechos establecidos por la Constitución, el artículo $19 \mathrm{~N}^{\circ} 26$ constituye uno de los pilares de una teoría moderna sobre irretroactividad e intangibilidad.

\subsubsection{El bien jurídico protegido: la esencia de los derechos y su libre ejercicio}

\section{(a) La esencia del derecho en la doctrina extranjera}

El concepto de esencia del derecho ha sido ampliamente estudiado por la doctrina y jurisprudencia alemana y española. Según Linazasoro Campos, las teorías respecto del contenido esencial de los derechos pueden resumirse en dos tipos: aquellas que analizan la garantía del contenido esencial de un punto de vista absoluto o relativo, y aquellas que la interpretan de un punto de vista objetivo o subjetivo ${ }^{49}$.

\section{(i) Teorias que analizan la garantía de un punto de vista absoluto o relativo}

Las teorías que analizan la esencia de los derechos de un punto de vista absoluto o relativo se plantean el problema desde la perspectiva de los límites que se le pueden imponer, concibiendo a esta garantía como "el límite de los límites" 50.

Para la teoría relativa del contenido esencial, los derechos no tienen un contenido esencial en el sentido usual del término. Por el contrario, el contenido esencial de un derecho está determinado por un juicio de razonabilidad de los límites al derecho, de modo que la esencia del derecho solo se vería afectada cuando no es posible justificar el límite que se le impone. En consecuencia, esta teoría postula que el derecho carece de

\footnotetext{
48 Linazasoro Campos (1996) p. 55-59.

49 Linazasoro Campos (1996) p. 49.

${ }^{50}$ Linazasoro Campos (1996) p. 49.
} 
contenido propio frente al límite; es decir, no se puede hablar de contenido esencial sin referirse a una limitación que se imponga al derecho. La garantía no consiste en la prohibición de imponer al derecho cualquier límite, sino en la exigencia de que el límite impuesto no sea arbitrario ${ }^{51}$.

Inversamente, la teoría absoluta del contenido esencial postula que, independientemente del juicio de razonabilidad de la limitación al derecho fundamental que la ley establece, este tiene un núcleo duro que no puede ser afectado y que es por tanto intangible para el legislador, confundiéndose dicho núcleo con la esencia del derecho. Para graficarlo se recurre a una imagen de dos círculos concéntricos, donde el círculo interno es el núcleo duro, que jamás puede ser tocado o traspasado por el legislador, por cuanto importa violar el contenido esencial del derecho. En cambio, el círculo exterior es la parte del derecho que puede ser tocado, regulado, complementado o limitado por preceptos legales cuando la constitución así lo manda o autoriza ${ }^{52}$.

Finalmente, existen también teorías mixtas del contenido esencial que intentan compatibilizar la teoría absoluta con la teoría relativa, poniendo énfasis en el mínimo intangible del derecho pero indagando también sobre la existencia de otros bienes y valores constitucionales que justifican limitar dicho derecho ${ }^{53}$.

(ii) Teorias que analizan la garantía de un punto de vista objetivo o subjetivo

Otras teorías analizan la garantía del contenido esencial tomando como punto de partida la posición objetiva o subjetiva de la normativa constitucional. En este sentido, el Tribunal Constitucional alemán se ha preguntado si la esencia del derecho debe interpretarse primariamente a partir de las posiciones individuales de los sujetos afectados, o a partir de una interpretación objetiva de lo que constituye la esencia de un determinado derecho. Al respecto, se ha argumentado que una interpretación objetiva puede aparecer al lado de una subjetiva, pero no sustituirla ${ }^{54}$.

\section{(b) La esencia del derecho en la doctrina nacional}

\section{i) El concepto de esencia del derecho según la C.E.N.C.}

En la doctrina nacional, el debate sobre el sentido y alcance del concepto de "esencia del derecho" nació en la C.E.N.C., con ocasión del análisis del derecho de propiedad. La discusión respecto de la esencia de este derecho resulta ilustrativa para entender las distintas posiciones doctrinales sobre el concepto de esencia de los derechos.

La Comisión discutió largamente sobre la conveniencia de incluir el concepto de esencia del derecho de propiedad en el Art. $19 \mathrm{~N}^{\circ}$ 24, especialmente sobre la conveniencia de definir lo que se entendía por esencia del derecho. Durante gran parte de la discusión Evans de la Cuadra se opuso tenazmente a la inclusión de dicho concepto,

\footnotetext{
51 Linazasoro Campos (1996) p. 50.

52 Linazasoro Campos (1996) p. 50.

53 Linazasoro Campos (1996) p. 50.

${ }^{54}$ Linazasoro Campos (1996) p. 51.
} 
argumentando que ello dejaría solo dos opciones al constituyente: una, definir en el texto constitucional lo que se entiende por esencia, lo que transformaría al derecho de propiedad en una institución estática, o la otra, no definirla, lo que significaría permitir un debate sin fin sobre lo que se entiende por esencia del derecho ${ }^{55}$. En definitiva se decidió hacer solo una referencia a la esencia del derecho en el inciso $3^{\circ}$ del Art. $19 \mathrm{~N}^{\circ}$ 24 , en cuanto deslinde entre limitación y expropiación, y establecer un norma general para proteger a todos los derechos fundamentales en su esencia. El criterio unánime fue que la Constitución debía asegurar que "las limitaciones, obligaciones o los modos de adquirir, usar, gozar, y disponer de la propiedad, en definitiva no signifiquen una privación de la esencia del derecho. Es decir, que nadie puede ser limitado en tales atributos en forma que ello importe, en el hecho, la privación del derecho en su esencia" 56 .

En la C.E.N.C. también hubo controversia sobre qué se entendía por esencia del derecho de propiedad, particularmente si este era un concepto inmutable o variable.

Diez fue de la opinión que la expresión "esencia" corresponde a aquello que caracteriza el derecho de propiedad como tal, sin lo cual este no existe o se transforma en un derecho diferente. Sería labor de la jurisprudencia ir precisando caso a caso dicho concepto, de acuerdo con las circunstancias económicas, históricas, filosóficas y políticas, de acuerdo con el espíritu general de la legislación. En consecuencia, Diez mantuvo que el concepto de esencia del derecho no sería absolutamente fijo y permanente, sino que permitiría la movilidad de la interpretación de los tribunales de justicia ${ }^{57}$.

Eyzaguirre sostuvo la opinión contraria, señalando que la esencia del derecho de propiedad, como la esencia de todas las cosas, era inmutable. Según Eyzaguirre, la esencia de una cosa es lo que hace que esa cosa sea eso y no otra distinta, y que por lo tanto la esencia no podía cambiar, existiendo siempre una constante inalterable. Mirado desde este punto de vista, el concepto de esencia del derecho tendría la ventaja de proporcionar la estabilidad buscada, dada por la constante de nuestro pensamiento jurídico y, por otro lado, permitir las novedades que se generan en la evolución del derecho de propiedad ${ }^{58}$.

Finalmente se llegó a un acuerdo respecto del contenido de la esencia del derecho de propiedad, quedando esta circunscrita a los modos de adquirir el dominio y los atributos y facultades del dominio, y que la función que debía cumplir el concepto de esencia era asegurar que dicho contenido no fuera vulnerado ${ }^{59}$.

La discusión sobre la esencia de los derechos en la C.E.N.C. pone en evidencia lo difícil que es precisar el concepto de esencia de un derecho. Sin embargo, también demuestra que existe un cierto consenso de que debe entenderse por esencia de un derecho todo aquello que es consustancial a él, en términos tales que, faltando, deje de ser tal o se confunda con otro derecho. Cabe resaltar que este criterio es expresamente aceptado dentro del derecho positivo privado chileno, específicamente en el artículo

55 C.E.N.C., Actas Oficiales, Sesión No 155.

56 C.E.N.C., Actas Oficiales, Sesión No 161.

57 C.E.N.C., Actas Oficiales, Sesión No 155.

${ }^{58}$ C.E.N.C., Actas Oficiales, Sesión No 155.

59 C.E.N.C., Actas Oficiales, Sesión No 156. 
1444 del Código Civil, que dispone que "son de la esencia de un contrato aquellas cosas sin las cuales o no produce efecto alguno, o degenera en otro diferente" 60 .

No obstante la dificultad anterior, es posible concluir que existen dos alternativas para determinar qué se entiende por esencia de un derecho: definir lo que se entiende por esencia en la legislación positiva, o permitir que la jurisprudencia vaya determinando el concepto caso a caso. Si bien la primera alternativa otorga mayor seguridad jurídi$\mathrm{ca}$, tiene el inconveniente de conducir al congelamiento del derecho. La segunda alternativa proporciona menos seguridad jurídica, pero permite que el derecho se desarrolle en forma dinámica, acomodándose a la realidad de la sociedad.

(ii) Aproximaciones al concepto de esencia posteriores a la Constitución de 1980

El concepto de esencia del derecho ha seguido siendo materia de estudio por parte de los juristas nacionales con posterioridad a la Constitución de 1980.

Algunos autores nacionales han seguido el análisis hecho por la doctrina extranjera en relación con el contenido esencial de los derechos, adhiriendo de una u otra manera a las teorías absolutas o relativas sobre dicho contenido esencial.

En este sentido, la postura de Mohor Abuauad se acerca a la teoría relativa sobre la esencia de los derechos, ya que rechaza la idea de una esencia como núcleo intangible del derecho, argumentando que ninguna parte del derecho es accidental o no esencial. Refiriéndose al derecho de propiedad, afirma que "no hay un núcleo, hay solo un derecho que se identifica por las particularidades de su contenido específico en un espacio y tiempo determinados, y cuya realidad está permanentemente en estado de cambio", reflejando la tensión entre individuo (propiedad) y sociedad (limitaciones). Para Mohor, la esencia del derecho "no debe definirse por un contenido específico y concreto... la esencia debe ser definida solo por la relación ontológica del derecho con la finalidad a que accede, puesto que ella permanecerá a través de los tiempos"; y esta finalidad consiste en "satisfacción de necesidades personales, instinto de seguridad, previsión de necesidades futuras, estímulo de la producción”. La determinación de esta esencia y de la constitucionalidad de las limitaciones al dominio debe quedar entregada a los tribunales de justicia de acuerdo con el nivel de equilibrio entre individuo y sociedad y la modalidad de satisfacción (en ese momento histórico) de las finalidades mencionadas precedentemente. En consecuencia, Mohor considera que la labor de los tribunales "no es puramente jurídica, sino básicamente psicológica, de lo que, en definitiva, resulta que la esencia del derecho no es una realidad jurídico-geométrica, sino, más bien, jurídico-psicológica y teleológica" 61 .

Rajevic Mosler adhiere a posición de Díez-Picazo, cuya aproximación al contenido esencial de los derechos coincide con los postulados básicos de las teorías mixtas sobre dicho contenido ${ }^{62}$. Díez-Picazo considera que para aproximarse a la esencia del derecho deben usarse dos criterios complementarios: uno dogmático, consistente en la

\footnotetext{
60 Apara y Zeballos (1985) p. 105.

${ }^{61}$ Mohor Abuauad (1989) pp. 298-306.

62 Rajevic Mosler (1996) pp. 129-130.
} 
parte del contenido que permite la recognoscibilidad del derecho como perteneciente a un determinado tipo, y uno de jurisprudencia de intereses, consistente en la parte del contendido que resulta necesaria para que queden protegidas las finalidades y los intereses que el derecho subjetivo debe servir y de que es instrumento ${ }^{63}$.

Por su parte, Cea Egaña sostiene que para definir la esencia de un derecho se requiere una integración armónica a través de la jurisprudencia constructiva, es decir, "en la correlación de la norma positiva con la realidad social y la justicia, determinando la ponderación de estos últimos dos elementos el sentido de aquella, cuando es necesaria la hermenéutica para dilucidarlo" 64 .

Finalmente, el Tribunal Constitucional ha señalado que "un derecho es afectado en su 'esencia' cuando se le priva de aquello que le es consubstancial de manera tal que deja de ser reconocible" 65 .

\section{(c) El libre ejercicio de los derechos}

El artículo 19 No 26 cautela no solo la esencia de los derechos fundamentales, sino también su libre ejercicio. En efecto, según la disposición citada las leyes que regulen, complementen o limiten uno de los derechos fundamentales consagrados en la Constitución no pueden afectar la esencia de ese derecho ni establecer condiciones, tributos y requisitos que impidan su libre ejercicio. Para Cea Egaña, ello ocurre "si para el titular no hay manera de que pueda realizar lo que el Derecho subjetivo lleva consigo, imposibilidad que resulta de la desproporción entre las restricciones establecidas por el legislador para cumplir los fines de la Constitución, por una parte, y el libre ejercicio de los derechos, por otra" ${ }^{\prime 6}$.

Cea Egaña concluye que se trata de un asunto cualitativo y no cuantitativo que debe ser solucionado por la jurisprudencia. En el fondo se trata de un problema de interpretación, la que "debe ser hecha buscando el sentido objetivo y que (...) es la finalidad de las normas no en sí mismas, sino que conectadas con la evolución social y la idea de justicia también progresiva" 67 .

En este sentido, el Tribunal Constitucional ha señalado que se impide el libre ejercicio de un derecho "en aquellos casos en que el legislador lo somete a exigencias que lo hacen irrealizable, lo entraban más allá de lo razonable o lo privan de tutela jurídica”68.

(d) Derechos protegidos por el Art. $19 N^{\circ} 26$

La intangibilidad que establece el Art. 19 No 26 no se extiende a todos los derechos subjetivos, sino solo a los derechos "que esta [la Constitución] establece".

\footnotetext{
63 Díez-PiCAzo (1991) t. I, pp. 1262-1263.

64 CEA Egaña (1988) p. 295.

65 Sentencia del Tribunal Constitucional sobre la Ley Orgánica Constitucional sobre Partidos Políticos, Rol No 43 (1987).

66 CeA EgAÑa (1988) p. 296.

67 CeA Egaña (1988) p. 296.

68 Sentencia del Tribunal Constitucional sobre la Ley Orgánica Constitucional sobre Partidos Políticos, Rol No 43 (1987).
} 
El alcance de la expresión "que la Constitución establece" debe interpretarse como aquellos derechos que la carta fundamental establece en todo su articulado y extensión, y no restringido al artículo 19 o al Capítulo III de los Derechos y Deberes Constitucionales. Lo anterior concuerda con la historia fidedigna del establecimiento de la Constitución, pues en la C.E.N.C. se señaló que todos los derechos deben respetarse en su esencia, no solo los relativos a los derechos individuales, sino también toda otra disposición constitucional que constituya garantía para el gobernado frente al gobernante aún cuando no esté en el capítulo de las garantías individuales ${ }^{69}$.

\subsubsection{Características de la protección que otorga el Art. $19 \mathrm{~N}^{\circ} 26$.}

\section{(a) Limitación a la acción del legislador}

El artículo 19 No 26 está concebido fundamentalmente como una limitación a la acción del legislador. Es la ley quien no podrá, en el ejercicio de su labor de regulación, complementación o interpretación de los derechos fundamentales reconocidos por la Constitución, afectar dichos derechos en su esencia.

Cea Egaña señala que la prohibición que establece esta norma alcanza a preceptos legales de toda especie (incluyendo leyes interpretativas, legislación delegada, tratados internacionales y cualquier otra norma que tenga fuerza de ley en el ordenamiento jurídico chileno) y de cualquier jerarquía (incluyendo leyes orgánicas constitucionales, leyes de quórum calificado y leyes comunes).

Según el tenor literal del artículo, la prohibición alcanza a las leyes que tengan por objeto regular, complementar o limitar los derechos que establece la Constitución. Sin embargo, en opinión de Cea Egaña también deben incluirse las normas interpretativas de la Constitución, ya que así se deduce del análisis de la historia fidedigna y del Art. 63 de nuestra Carta Fundamental, y por estar la acción interpretativa íntimamente vinculada con las labores de regulación, complementación y regulación ${ }^{70}$.

Existe discusión entre los autores sobre si es posible aplicar el Art. $19 \mathrm{~N}^{\circ} 26$ a normas distintas a la ley formal. En opinión de Cea Egaña, se excluyen de la aplicación del Art. 19 No 26 las normas distintas o de rango inferior a la ley, tales como los reglamentos, decretos u otros actos administrativos, ya que para estos fueron creados recursos específicos, tales como las acciones constitucionales de protección y amparo, consagradas en los artículos 20 y 21 de la Constitución Política, respectivamente ${ }^{71}$.

Sin embargo, otra parte de la doctrina nacional considera que, debido a principios de hermenéutica constitucional, no debe restringirse la aplicación del Artículo 19 No 26 al ámbito de la ley formal. En este sentido, Evans de la Cuadra sostiene que el hecho de que el Art. $19 \mathrm{~N}^{\circ} 26$ se refiera específicamente a preceptos legales no significa que este artículo excluya de la prohibición a atentados a normas de rango inferior o de actos de autoridad. Desconocer que el Art. $19 \mathrm{~N}^{\circ} 26$ excluye de ese imperativo protector a toda

\footnotetext{
${ }^{69}$ C.E.N.C., Actas Oficiales, Sesión $\mathrm{N}^{\circ} 150$.

70 CEA Egaña (1988) pp. 292-295.

${ }^{71}$ CEA EgAÑa (1988) p. 113.
} 
autoridad, legislativa, gubernativa, administrativa o de otro carácter, sería llegar al absurdo de que lo que no puede hacer una ley complementaria de la Constitución, que requiere para su aprobación tres quintos de los diputados y senadores en ejercicio (Art. 63 , inc. $1^{\circ}$, de la Constitución), sí lo puede hacer una ley corriente o cualquier autoridad administrativa ${ }^{72}$.

No obstante lo anterior, la aplicación real del Art. 19 N² 26 a normas distintas de la ley es ilusoria, ya que este derecho no está incluido dentro de aquellos que ampara el recurso de protección establecido en el Art. 20 de nuestra Constitución Política. En consecuencia, la violación del Art. $19 \mathrm{~N}^{\circ} 26$ por parte de un acto administrativo, ya sea de efectos generales o particulares, no podrá ser remediada por la vía judicial, lo que en la práctica implica la indefensión de las personas frente a la acción de la Administración. Este vacío legal es una de las razones por las cuales ha proliferado la práctica de la propietarización de los derechos, ya que si nuestro ordenamiento otorgara protección directa a los derechos amparados por la Constitución frente a la acción de la Administración, no habría necesidad de recurrir al resquicio de la propietarización.

\section{(b) Excepciones al Art. $19 N^{\circ}$ 26: los estados de excepción constitucional}

El inciso $2^{\circ}$ del Art. 19 No 26 señala que se exceptúan a lo dispuesto en el inciso 1 - "las normas relativas a los estados de excepción constitucional y demás que la propia Constitución contempla".

La primera parte del inciso es clara: declarados los estados de excepción contemplados en los artículos 39 a 41 de la Constitución, se permite al legislador afectar los derechos fundamentales en su esencia o impedir su libre ejercicio.

Respecto de los "demás casos que la propia Constitución contempla", debe tratarse de situaciones expresamente previstas en el texto constitucional y no referidas a los estados de excepción. Cea Egaña es de la opinión de que esta segunda parte del inciso $2^{\circ}$ podría referirse a los artículos 9, 23, 57 y 19 No 15 y No 19 de la Constitución. Señala Cea que no encuentra en la Constitución otras situaciones análogas, y cree que no es admisible crearlas sobre la base de suponer que están implícitas en ella ${ }^{73}$.

\section{(c) Alcance de la intangibilidad que establece el Art. $19 N^{\circ} 26$}

El Art. $19 \mathrm{~N}^{\circ} 26$ de la Constitución otorga a los derechos establecidos por la Constitución una intangibilidad directa, basada en su calidad de derechos y no en su calidad de bienes susceptibles de apropiación. Esta intangibilidad consiste en la imposibilidad por parte del legislador de afectar la esencia o libre ejercicio de dichos derechos.

A diferencia del Art. $19 \mathrm{~N}^{\circ} 24$, la intangibilidad del Art. $19 \mathrm{~N}^{\circ} 26$ es prácticamente absoluta, ya que no permite la afectación de la esencia de los derechos garantizados por la Constitución salvo en los estados de excepción constitucional o en los demás casos que la propia Constitución contempla. En otras palabras, salvo contadas excepciones el Art. $19 \mathrm{~N}^{\circ} 26$ no permite que los derechos sean afectados en su esencia, ni

72 EVANS de la CuAdra (1986) t. II, pp. 298-299.

73 CeA Egaña (1988) p. 297. 
siquiera si media algún tipo de compensación para el titular, como hace el Art. $19 \mathrm{~N}^{\circ} 24$ mediante el mecanismo de la expropiación.

A simple vista, esta imposibilidad de afectar la esencia de los derechos reconocidos por la Constitución podría ser considerada beneficiosa para los titulares de los derechos afectados, ya que existe una absoluta prohibición de afectar su esencia. Sin embargo, dado que el Art. $19 \mathrm{~N}^{\circ} 26$ se encuentra en la práctica totalmente desamparado frente a la acción de la Administración, las personas afectadas prefieren recurrir al Art. $19 \mathrm{~N}^{\circ} 24$ (que sí permite la afectación de la esencia a través del mecanismo de expropiación) para obtener la protección de sus derechos.

Incluso si el Art. $19 \mathrm{~N}^{\circ} 26$ llegase a tener algún tipo de protección frente a la acción de la Administración, ya sea por medio de su inclusión entre los derechos amparados por el recurso de protección o por medio de otros mecanismos, la total imposibilidad de afectar la esencia de ciertos derechos no es necesariamente beneficiosa para la sociedad. Esta intangibilidad absoluta tiene sentido respecto de los derechos relacionados con la vida e integridad moral de la persona, tales como el derecho a la vida y a la integridad física y psíquica, el derecho a la igualdad ante la ley y el derecho a la libertad personal. Sin embargo, respecto de derechos de índole patrimonial, tales como el derecho a desarrollar cualquier actividad económica lícita o la igualdad ante los tributos y cargas públicas, consideramos que el Art. $19 \mathrm{~N}^{\circ} 26$ debiera permitir la posibilidad de afectar su esencia en casos de interés general mediante una justa compensación al titular. Como hoy en día esa alternativa no existe, en teoría el Estado no puede afectar la esencia de otros derechos patrimoniales distintos del derecho de propiedad fuera de los estados de excepción constitucional o los demás que la Constitución contempla. La consecuencia práctica de este vacío constitucional es que también el Estado se ve tentado de recurrir al resquicio de la propietarización, ya que por lo menos por esa vía tiene derecho a expropiar al titular de su derecho.

Por lo tanto, si verdaderamente queremos eliminar el resquicio de la propietarización y otorgar protección directa a los derechos mediante el Art. $19 \mathrm{~N}^{\circ} 26$, es necesario otorgarle una cierta flexibilidad que permita su aplicación práctica.

\section{CONCLUSIONES}

En virtud de las consideraciones anteriores, hoy en día es posible afirmar que los principios de irretroactividad e intangibilidad se encuentran consagrados a nivel constitucional en nuestro ordenamiento jurídico. En efecto, la Constitución Política de 1980 otorga seguridad jurídica a los derechos en el contexto de la aplicación temporal de la ley, tanto en forma directa, a través del Art. 19 No 26, como en forma indirecta, a través del Art. 19 No 24.

El Art. 19 No 24 confiere protección indirecta a los derechos por la vía de su incorporación al patrimonio de sus titulares. Este artículo reconoce expresamente el derecho de propiedad sobre las cosas incorporales, y ya que según la doctrina mayoritaria en nuestro medio los derechos constituyen cosas incorporales susceptibles de apro- 
piación, el efecto de este artículo ha sido extender a los derechos así adquiridos la intangibilidad propia del derecho de propiedad.

Por su parte, el Art. $19 \mathrm{~N}^{\circ} 26$ establece una intangibilidad directa a los derechos establecidos por la Constitución, otorgando seguridad jurídica a los derechos por el hecho de ser tales, y no por la vía de su propietarización.

Los artículos citados constituyen, en nuestra opinión, el fundamento de los principios de irretroactividad e intangibilidad en nuestro ordenamiento jurídico. En el caso del Art. $19 \mathrm{~N}^{\circ}$ 24, un derecho incorporado al patrimonio de su titular goza de la protección del derecho de propiedad. Ello significa que ese derecho solo puede ser restringido por la acción del legislador y como consecuencia de la función social de la propiedad, y que dicha restricción no podrá afectar la esencia de ese derecho salvo que medie expropiación. En el caso del Art. $19 \mathrm{~N}^{\circ}$ 26, un derecho establecido por la Constitución goza de una protección inherente a su calidad de derecho constitucional, consistente en que el legislador no podrá afectar dicho derecho en su esencia, ni imponer condiciones, tributos o requisitos que impidan su libre ejercicio.

En consecuencia, la intangibilidad establecida en la Constitución implica que ninguna ley, reglamento o resolución administrativa dictada con posterioridad al nacimiento de un derecho, protegido directa o indirectamente por nuestra Carta Fundamental, puede restringirlo o limitarlo en su esencia. Una restricción que afecta la esencia de un derecho implica privación del mismo, y solo puede ser impuesta por vía de la expropiación.

Esta prohibición alcanza expresamente a la ley, ya que tanto el Art. 19 No 24 como el Art. 19 No 26 se refieren a las limitaciones o regulaciones impuestas por ley. Sin embargo, aunque la Constitución no lo diga expresamente, por razones de supremacía constitucional esta prohibición debe hacerse extensiva a la potestad reglamentaria y a las demás manifestaciones de la autoridad administrativa, especialmente si consideramos que le está vedado a la Administración regular sobre garantías constitucionales.

En consecuencia, una ley de efecto retroactivo, o una ley de efecto inmediato que afecte situaciones existentes nacidas con anterioridad a su dictación, solo podrá aplicarse mediante el mecanismo de la expropiación si penetra en el núcleo sustancial de los derechos afectados.

Si la intangibilidad de los derechos es afectada por una ley de efecto retroactivo o inmediato, los titulares de los derechos afectados pueden defender la intangibilidad de sus derechos por la vía del recurso de inaplicabilidad establecido en el Art. 80 de la Constitución. Sin embargo, si la intangibilidad es afectada por un acto administrativo, la Constitución entrega medios directos para hacer efectiva la intangibilidad solo en el caso del Art. $19 \mathrm{~N}^{\circ}$ 24, al incluirlo dentro de los derechos amparados por el recurso de protección establecido en el Art. 20. El Art. $19 \mathrm{~N}^{\circ} 26$ no está comprendido dentro de los derechos cautelados por esta acción constitucional, lo que ha contribuido a la proliferación de la práctica de la propietarización de los derechos.

Cabe destacar que la intangibilidad establecida por la Constitución de 1980 no impone el congelamiento del ordenamiento jurídico, ya que permite aplicar limitaciones o restricciones que no afecten lo sustancial. Lo intangible es la esencia de los derechos, 
pero incluso la esencia puede violarse si se utiliza el mecanismo de la expropiación. Por lo tanto, si el legislador considera que el bien común requiere que un derecho adquirido debe ser completamente eliminado, puede recurrir a la expropiación. Si bien la Constitución no contempla el mecanismo de la expropiación para el Art. $19 \mathrm{~N}^{\circ} 26$, consideramos necesario incluir una disposición similar respecto de ciertos derechos de carácter patrimonial, tales como el derecho a desarrollar cualquier actividad económica lícita, para hacer más flexible la intangibilidad que confiere este artículo y asegurar su aplicación práctica. Sin embargo, hasta que se establezca un mecanismo parecido para el Art. $19 \mathrm{~N}^{\circ} 26$ es indudable que el Estado seguirá amparándose en la práctica de la propietarización para poder limitar los derechos esenciales de la persona mediante el mecanismo de la expropiación.

\section{REFERENCIAS DE BIBLIOGRAFÍA, NORMAS Y JURISPRUDENCIA}

\section{BiBLIOGRAFÍA CiTADA}

AlesSANDri RodrígueZ, Arturo y SOMARRIVA UndurRaga, Manuel (1961-1962): Curso de Derecho Civil: basado en las explicaciones de los profesores de la Universidad de Chile Arturo Alessandri Rodríguez y Manuel Somarriva Undurraga, redactado y puesto al día por Antonio Vodanovic H, $3^{a}$ edición. (Santiago, Editorial Nascimento) 1 v. en 2 t.

Apara Riadi, Soraya y Zeballos Marín, Gustavo (1985): La Esencia de los Derechos y su Libre Ejercicio en la Nueva Constitución (Santiago, Memoria de Grado).

CEA EgañA, José Luis (1988): Tratado de la Constitución de 1980: características generales, garantías constitucionales (Santiago, Editorial Jurídica de Chile), 402 pp.

Claro Solar, Luis (1978): Explicaciones del Derecho Civil Chileno y Comparado, 2a edición (Santiago, Editorial Jurídica de Chile) 6 t.

Corral Talciani, Hernán (1996): "Propiedad y Cosas Incorporales. Comentarios a Propósito de una Reciente Obra del Profesor Alejandro Guzmán Brito", Revista Chilena de Derecho, vol. XXIII, ${ }^{\circ} 1$.

DíEZ-PICAZO, Luis (1991): "Algunas Reflexiones sobre el Derecho de Propiedad Privada en la Constitución”, en: Estudios sobre la Constitución Española. Homenaje al profesor Eduardo García de Enterría (Madrid, Editorial Civitas) 5 v.

Evans De La Cuadra, Enrique (1986): Los Derechos Constitucionales (Santiago, Editorial Jurídica de Chile) 2 v.

Evans De La Cuadra, Enrique (1999): Los Derechos Constitucionales, 2a edición (Santiago, Editorial Jurídica de Chile) 3 v.

GUZMÁN BRITO, Alejandro (1995): Las Cosas Incorporales en la Doctrina y en el Derecho Positivo (Santiago, Editorial Jurídica de Chile) 260 pp.

LiNAZASORO CAMPOS, Gonzalo (1996): "Derechos Fundamentales e Interpretación”, en: Instituciones Modernas de Derecho Civil. Homenaje al Profesor Fernando Fueyo Laneri (Santiago, Editorial Jurídica ConoSur) 574 pp.

López Menudo, Francisco (1982): El Principio de Irretroactividad en las Normas Juridico-Administrativas (Instituto García Oviedo, Universidad de Sevilla) 368 pp. 
Madariaga Gutiérrez, Mónica (1965): Derecho Administrativo y Seguridad Jurídica (Santiago, Editorial Jurídica de Chile) 154 pp.

Mohor AbuAuAd, Salvador (1989): "Taxonomía de las Limitaciones al Dominio y Derecho de Indemnización”, Revista Chilena de Derecho, vol. XVI.

Rajevic Mosler, Enrique (1996): La Propiedad Privada de los Planes Reguladores: estudio sobre las limitaciones del dominio en la esfera de la legislación urbanistica (Santiago, Tesis Licenciado en Ciencias Jurídicas y Sociales, Pontificia Universidad Católica de Chile) $272 \mathrm{pp}$.

ReYes Riveros, Jorge (1993): "El Estado como Regulador, Mediante Ley, del Ejercicio de los Derechos Fundamentales y de Contralor de dicha Normativa", Revista Chilena de Derecho, vol. 20.

Sото Kloss, Eduardo (1996): Derecho Administrativo: Bases Fundamentales (Santiago, Editorial Jurídica de Chile) $2 \mathrm{t}$.

SuÁrez Collía, José María (1994): El Principio de Irretroactividad de las Normas Jurídicas (Madrid, ACTAS) 110 pp.

Vergara Blanco, Alejandro (1990): "Los Derechos Reales Administrativos: un tipo de derecho público subjetivo necesitado de reconocimiento en Chile", XX Jornadas Chilenas de Derecho Público (Valparaíso, Edeval, 1990).

Vergara Blanco, Alejandro (1991-1992): "La Propietarización de los Derechos", Revista de Derecho de la Universidad Católica de Valparaíso, vol. XIV.

\section{NORMAS CITADAS}

\section{Código Civil}

Constitución Política de la República, 8 de agosto de 1980

Ley sobre Efecto Retroactivo de las Leyes, 7 de octubre de 1861

\section{JURISPRUDENCIA CITADA}

De la Cerda Tapia, Fernando y otro con servicio Agrícola y Ganadero (1984): Corte Suprema, 19 de abril de 1984 (recurso de inaplicabilidad), Revista de Derecho y Jurisprudencia, t. 81 (1984), I, Sección 5a, pp. 16-21.

Torres Zamora, Claudia con Superintendente de Seguridad Social (1984): Corte de Apelaciones de Santiago, 7 de agosto de 1984 (recurso de protección) Revista de Derecho y Jurisprudencia, t. 81 (1984), II, Sección 5a , pp. 153-161.

García Schiele, Claudio, con Vicerrector Académico de la Universidad Austral de Chile (1992): Corte Suprema, 2 de julio de 1992 (recurso de protección) Revista de Derecho y Jurisprudencia, t. 89 (1992), II, pp. 153-159.

Sentencia sobre la constitucionalidad del proyecto de ley sobre "Bases Generales del Medio Ambiente, Rol No 185 (1994): Tribunal Constitucional, 20 de febrero de 1994.

Sentencia sobre la constitucionalidad del Decreto Supremo $N^{\circ} 1 / 96$ del Ministerio de Bienes Nacionales, Rol N²45-246 (1996): Tribunal Constitucional, 2 de diciembre de 1996. 
SACCo Aquino, Sabina "La Constitución de 1980 como fundamento y origen de una teoría..."

Sentencia sobre la constitucionalidad de la Ley Orgánica Constitucional de los Partidos Políticos (1987): Tribunal Constitucional, 24 de febrero de 1987.

TEXTOS HisTÓRICOS

Comisión de Estudio de la Nueva Constitución, Actas Oficiales:

- Sesión $\mathrm{N}^{\circ} 155(2 / 10 / 75)$

- Sesión No $156(7 / 10 / 75)$

- Sesión $N^{\circ} 161(28 / 10 / 75)$

- Sesión $N^{\circ} 212(19 / 05 / 76)$ 